\title{
Assessment of SPLAT formulations to control Grapholita molesta (Lepidoptera: Tortricidae) in a Brazilian apple orchard
}

\author{
Cristiano João Arioli' ${ }^{1}$ Patrik Luiz Pastori ${ }^{*}$, Marcos Botton ${ }^{3}$, Mauro Silveira Garcia ${ }^{4}$, Rafael Borges ${ }^{5}$, \\ and Agenor Mafra-Neto ${ }^{5}$
}

Mating disruption is a technique that uses synthetic copies of sex pheromones to control insect pests. We aimed to control Oriental fruit moth (OFM) Grapholita molesta (Busck) (Lepidoptera: Tortricidae) with formulations of SPLAT Grafo (SG) and SPLAT Grafo Attract and Kill (SGAK) in small (1 ha) apple (Malus domestica Borkh.) orchards. Our experiment was conducted in a commercial orchard with 'Gala' trees (spacing $1.5 \times 4.5 \mathrm{~m}$ ) in Vacaria, Rio Grande do Sul State, Brazil. We evaluated the effect of four treatments on $G$. molesta population densities: a) SG at $1 \mathrm{~kg} \mathrm{ha}^{-1}$ (300 point sources of $3.3 \mathrm{~g}$ each), b) SGAK at $1 \mathrm{~kg} \mathrm{ha}^{-1}$ (1000 point sources of $1 \mathrm{~g}$ each), c) insecticides as recommended by Integrated Apple Production (IAP), and d) untreated control (no treatment). Specialized Pheromone and Lure Application Technology (SPLAT) treatments were applied on 1 August 2004 and reapplied after 120 d (1 December 2004). The treatment effect was evaluated by weekly counts of males captured in Delta traps baited with commercial synthetic sex pheromone lures (eight traps per treatment). We assessed fruit damage caused by G. molesta in eight replicates of 200 fruits each on 26 October, 30 November 2004, and 5 and 31 January 2005. Applying $1 \mathrm{~kg} \mathrm{ha}^{-1}$ of SG and SGAK in August and December 2004 significantly reduced the number of male moths caught in Delta traps. Damage to fruits at harvest, however, did not differ significantly from the control. This indicates a decline in the efficacy of mating disruption when SG and SGAK are used to protect small areas (1 ha) under high Oriental fruit moth pressure.

Key words: Attract and kill, integrated apple production, Malus domestica, Oriental fruit moth, pheromone trap.

\section{INTRODUCTION}

Oriental fruit moth (OFM) Grapholita molesta (Busck) (Lepidoptera: Tortricidae) is a major pest of stone fruits (Salles and Marini, 1989; Botton et al., 2005), which specifically causes substantial damage to apple orchards in Brazil (Kovaleski and Ribeiro, 2003; Pastori et al., 2008; 2012). Damage by G. molesta has been frequently reported in stone fruits and apples in the three major fruit-producing regions of Southern Brazil (Fraiburgo and São Joaquim in Santa Catarina State and Vacaria in Rio Grande do Sul State).

${ }^{1}$ Empresa de Pesquisa Agropecuária e Extensão Rural do Estado de Santa Catarina, Estação Experimental de São Joaquim, 88.600-000, São Joaquim, Santa Catarina, Brasil.

${ }^{2}$ Universidade Federal do Ceará, Centro de Ciências Agrárias, 60.356-000, Fortaleza, Ceará, Brasil.

*Corresponding author (plpastori@ufc.br).

${ }^{3}$ Empresa Brasileira de Pesquisa Agropecuária Embrapa, Centro Nacional de Pesquisa Uva e Vinho, 95.700-000, Bento Gonçalves, Rio Grande do Sul, Brasil.

${ }^{4}$ Universidade Federal de Pelotas, Faculdade de Agronomia Eliseu Maciel, 96.160-000, Capão do Leão, Rio Grande do Sul, Brasil.

${ }^{5}$ ISCA Technologies, Inc., 1230 Spring Street, Riverside, California A 92507, USA.

Received: 8 July 2013.

Accepted: 3 April 2014.

doi: $10.4067 /$ S0718-58392014000200009
Damage caused by OFM is the result of larval feeding in both shoots and fruits (Kovaleski and Ribeiro, 2003). Feeding larvae undermine the formation of new shoot growth and will destroy newly forming flower buds. The OFM larvae preferentially feed near the stem of the fruit, thus penetrating and causing damage near the calyx. This results in impaired fruit with internal galleries that may still contain live larvae after harvest. Damaged fruit has little or no market value, and its presence in shipments may preclude export (Pastori et al., 2008; Neto and Silva et al., 2010).

Grapholita molesta populations have been suppressed primarily with broad-spectrum insecticides, mainly organophosphates (Kovaleski and Ribeiro, 2003). They are highly toxic and deleterious to non-target organisms, such as natural enemies (Manzoni et al., 2006; Moura et al., 2012) and pollinators (Pinheiro and Freitas, 2010). Moreover, the long pre-harvest interval for the main conventional insecticides recommended in the Integrated Apple Production (IAP) (Kovaleski and Ribeiro, 2003) limits their use during the harvest period (Pastori et al., 2008) when OFM populations are high. Significant fruit damage (up to $40 \%$ ) caused by OFM has been observed mainly in areas with late-maturing varieties of apples. Therefore, interest has drastically increased in the development of alternatives that effectively control $G$. 
molesta, while remaining consistent with market standards (Joshi et al., 2011). Using synthetic sex pheromones to interfere with mating and reproduction offers a nontraditional way to manage pests before using conventional insecticides (Larraín et al., 2009).

Control of OFM through mating disruption has been successful worldwide (Rothschild, 1975; Vilcker et al., 1985; Molinari et al., 2000; Trimble et al., 2001; Kovanci et al., 2005a), including promising results in Brazil (Salles and Marini, 1989; Botton et al., 2005; Monteiro et al., 2008; Pastori et al., 2008; 2012). A range of commercial semiochemical mating disruption products is available to control $G$. molesta. These products come in a variety of formulations, including sachets, ropes, and twist ties (Degen et al., 2005). Semiochemical formulations generally differ in both their longevity and implementation cost (Lame et al., 2010; Bohnenblust et al., 2011). Solid dispensers are hung on plants manually, which requires a substantial amount of labor for field application. One alternative is to use liquid microencapsulated pheromone formulations that can be mixed in water and applied as sprays with the same equipment for spraying insecticides. These methods have short longevity in the field and therefore require frequent reapplication (Trimble et al., 2004; Botton et al., 2005; Kovanci et al., 2005b).

SPLAT (Specialized Pheromone and Lure Application Technology) (ISCA Technologies, Inc., Riverside, California, USA) is a waxy, flowable matrix (Atterholt et al., 1999; Mafra-Neto, 2010; Pastori et al., 2012) that allows the incorporation of varying concentrations of pheromone and/or insecticide in the formulation (Stelinski et al., 2005). SPLAT can be applied manually or mechanically in the field as discrete point sources, which, along with variable size and density of deposits, provides semiochemical control that is tailored to this field (Stelinski et al., 2005).

The purpose of this study was to determine the effectiveness of SPLAT Grafo (SG) and SPLAT Grafo Attract and Kill (SGAK) to manage G. molesta in small areas (1 ha) of Brazilian apple orchards.

\section{MATERIALS AND METHODS}

\section{Experimental area and treatments}

The experiment was conducted from July 2004 to January 2005 (2004-2005 growing season) in Vacaria, Rio Grande do Sul State, Brazil. Field trials took place in a 'Gala' apple (Malus domestica Borkh.) orchard established in 1990. Spacing was $1.5 \times 4.5 \mathrm{~m}$ (rows $\times$ plants) and trees were 3.5 to $4.0 \mathrm{~m}$ tall.

Four experimental units (EUs) were established, each consisting of 1.0 ha subdivided into four plots or replicates of 0.25 ha. A distance of $10 \mathrm{~m}$ separated each plot; the experiment had a fully randomized design. Each experimental unit was assigned one of the following treatments: a) SPLAT Grafo (SG) at a rate of $1 \mathrm{~kg} \mathrm{ha}^{-1}$
(300 point sources of $3.3 \mathrm{~g}$ each), b) SPLAT Grafo Attract and Kill (SGAK) at a rate of $1 \mathrm{~kg} \mathrm{ha}^{-1}$ (1000 point sources of $1 \mathrm{~g}$ each), c) Integrated Apple Production (IAP) using the insecticide regime recommended by IAP (Protas, 2003), and d) untreated control. The SPLAT treatments were uniformly distributed in the experimental units, while the borders received an additional $10 \%$ application of SPLAT to decrease 'edge effect' (Molinari, 2002). The following insecticides were applied to the IAP-treated experimental unit: Fenitrothion (Sumithion $500 \mathrm{CE}^{\circledR}$, $150 \mathrm{~mL} 100 \mathrm{~L}^{-1}$ ) applied on 25 October, 6 November, and 22 December 2004, and 17 January 2005 to control

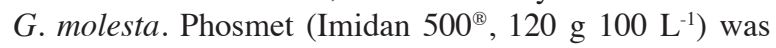
applied on 18 November 2004 to control G. molesta and Anastrepha fraterculus (Wiedemann) (Diptera: Tephritidae). Methidathion (Supracid 400 ${ }^{\circledR}, 100 \mathrm{~mL}$ $100 \mathrm{~L}^{-1}$ ) was applied on 26 November and 9 December 2004 to control G. molesta, Bonagota salubricola (Meyrick) (Lepidoptera: Tortricidae), and A. fraterculus. All experimental units were under the same cultural management.

\section{Formulation of synthetic sex pheromone and application method}

The SPLAT Grafo formulation contained (Z)-8-dodecenyl acetate, (E)-8-dodecenyl acetate, and (Z)-8-dodecenol (44 $\mathrm{g} \mathrm{kg}^{-1}$ ), while SPLAT Grafo Attract and Kill contained (Z)-8-dodecenyl acetate, (E)-8-dodecenyl acetate, (Z)-8-dodecenol (22 $\mathrm{g} \mathrm{kg}^{-1}$ ), and (RS)-alpha-cyano-3phenoxybenzyl (1RS)-cis-, trans-3-(2,2-dichlorovinyl)2,2-dimethylcyclopropane carboxylate (Cypermethrin) $\left(50 \mathrm{~g} \mathrm{~kg}^{-1}\right)$.

Two applications of each SPLAT formulation were made on 1 August and 1 December 2004 to control all the generations of $G$. molesta during the season. The SPLAT point sources were distributed manually in the experimental units with wooden spatulas previously calibrated to deliver either 1.0- or 3.3-g sized dollops. The point sources were placed at the base of the branches at 1.5 to $2.0 \mathrm{~m}$ above the soil surface, while SPLAT was completely shaded from the sun.

\section{Efficiency of treatments}

Treatment evaluations were performed by recording captures of male G. molesta in Delta traps baited with the synthetic sex pheromone. Inspection of fruit at harvest allowed us to determine if damage was caused by $G$. molesta, the Brazilian apple leafroller (Bonagota salubricola), another Lepidoptera (Geometridae and Noctuidae), or the South American fruit fly $(A$. fraterculus).

Standard $28 \times 20 \mathrm{~cm}$ white plastic Delta traps (ISCA Technologies Ltda., Ijuí, Rio Grande do Sul, Brazil) baited with ISCAlure Grafolita ${ }^{\circledR}$ (ISCA Technologies Ltda., Ijuí, Rio Grande do Sul, Brazil) were used to monitor the male G. molesta population. Eight traps were placed in each 
experimental unit (two per replicate) and spaced at least $30 \mathrm{~m}$ apart. Traps were hung on apple trees at 1.5 to 2.0 $\mathrm{m}$ above the ground. Trap catches were tallied and $G$. molesta males in the traps were removed on a weekly basis. Pheromone lures were replaced every $30 \mathrm{~d}$ and adhesive trap liners were replaced as needed.

Fruit for damage assessments was sampled from eight areas in each experimental unit (two areas per replicate). Plants were randomly chosen for sampling. A total of 200 fruits per replicate were assessed for damage and resulted in a combined total of 1600 fruits per treatment.

The following data were collected for each treatment: a) population dynamics of adult males by plotting the mean number of males per trap per week as a function of time, b) mating disruption index (MDI) calculated as $M D I$ $=(C T) / T \times 100$ where $C$ is the mean number of males captured per trap in the experimental unit and $T$ is the number of the males caught in the conventional treatment (IAP) (Molinari et al., 2000), c) cumulative mean number of males per trap per week, and d) percentage of fruits damaged by $G$. molesta larvae, B. salubricola, and other moths (Noctuidae and Geometridae). Results were assessed on 26 October 2004, 30 November 2004, 5 January 2005, and at harvest on 31 January 2005.

\section{Data analysis}

The mean percentage of fruit damaged by insects during each assessment was transformed to arcsine $\mathrm{x} / 1000^{0.5}$. Data were subjected to ANOVA and means compared by Tukey's test at 0.05 probability of error.

\section{RESULTS AND DISCUSSION}

The IAP-treated and untreated control experimental units revealed three population peaks of $G$. molesta during the experimental trial (Figure 1). Trap captures were similar for the IAP and untreated control treatments throughout the experiment.

The consistent capture of $G$. molesta males in all

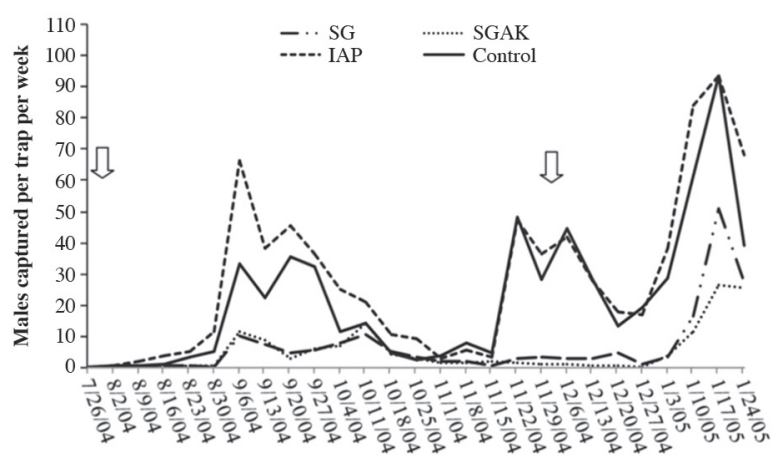

Arrows indicate pheromone application.

Figure 1. Mean number of male Grapholita molesta captured per week in baited Delta traps in apple plots receiving two applications (1 August and 1 December 2004) of SPLAT Grafo (SG) or SPLAT Grafo Attract and Kill (SGAK), Integrated Production of Apple (IAP), or untreated control. the experimental units during the experiment indicated high pest pressure (Figure 1). The percentage of fruits damaged by OFM larvae during the first assessment (26 October 2004) showed no significant differences between treatments (Figure 2), which reinforces the existence of a homogeneous infestation of the pest in the experimental area.

In general, an infestation of $G$. molesta is considered to be low when captures in monitoring traps are between 30 and 40 males per trap, per week, and post-diapause (González et al., 1990; Kovanci et al., 2005a). This parameter is usually associated with damage caused by the pest during harvest in the previous season and is considered low when fruit damage is lower than $1 \%$ (González et al., 1990; Kovanci et al., 2005a). In this experiment, trap captures of over 40 male moths per week occurred in the post-diapause generation. Furthermore,

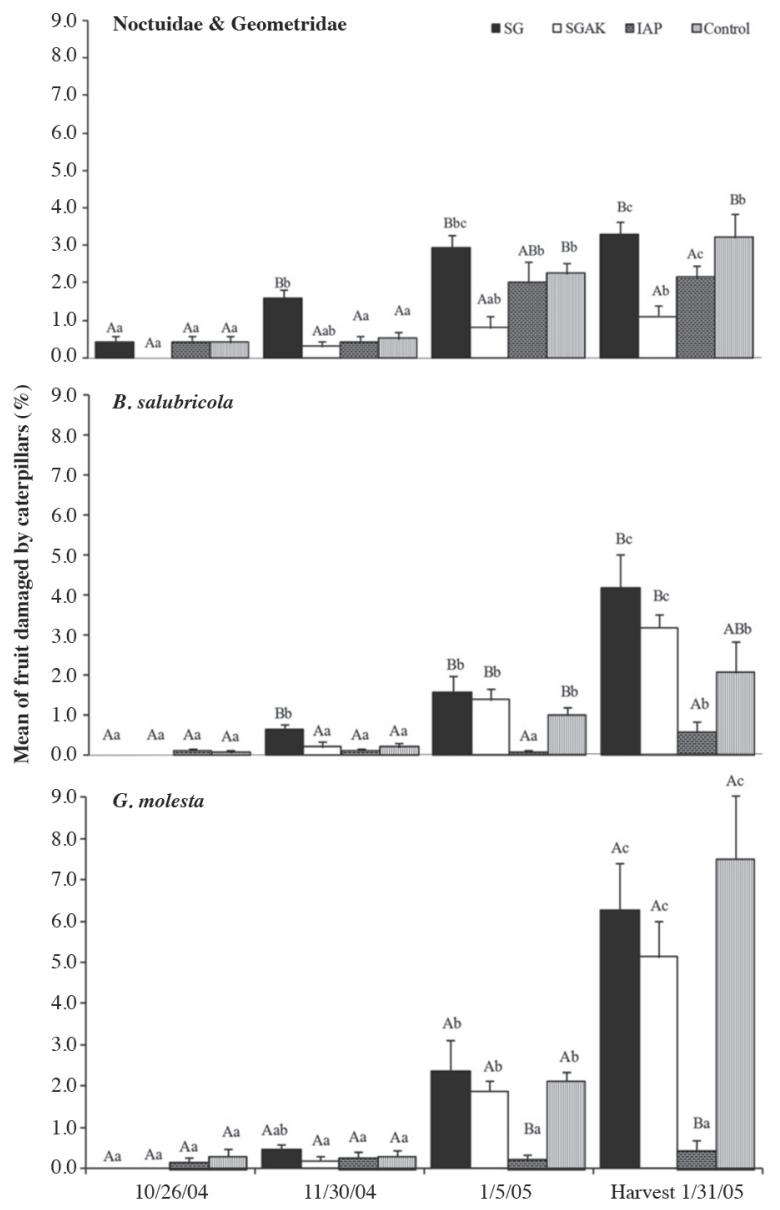

Means followed by different uppercase and lower-case letters differ according to Tukey's test at 0.05 probability of error.

Figure 2. Mean percentage $(\mu \pm \mathrm{SE})$ of fruit damaged by larvae of Geometridae and Noctuidae, Bonagota salubricola, and Grapholita molesta on 26 October 2004, 30 November 2004, 5 January 2005, and at harvest (31 January 2005) in apple trees receiving two applications (1 August and 1 December 2004) of SPLAT Grafo (SG) or SPLAT Grafo Attract and Kill (SGAK), Integrated Apple Production (IAP), or untreated control. 
fruit damage caused by OFM at harvest in the previous season (2003-2004) was high (3\%) and indicated high pest pressure (Figure 1).

The mean number of males captured in monitoring traps was significantly lower $(\mathrm{F}=33,15 ; \mathrm{p}=0.000004)$ in the areas treated with SG $(166.6 \pm 16.0)$ and SGAK $(113.8 \pm 35.6)$ compared with those belonging to the IAP and untreated control treatments. There were no significant differences in trap catch between the SGand SGAK-treated experimental units, nor were there significant differences between the IAP and untreated control experimental units (Table 1).

There was no significant difference in damage to apple fruits caused by G. molesta among treatments or between treatment dates for the evaluations performed on 26 October and 30 November 2004 (Figure 2), thus indicating that the post-diapause generation caused no damage. At this stage, vegetative structures and fruits were not present to support larval development. However, G. molesta larvae have been observed to feed on "burr knots" (adventitious root zones) after harvest. These knots can be a source of food that allows for the development of some individuals in the orchard (Bisognin et al., 2012).

A majority of growers have applied insecticides (mainly phosphates) to control G. molesta adults during bud break, which is a practice that aims to control pest populations in orchards with high pest pressure. This study indicates that, independently of the pest control treatment, applying insecticides can be ineffective to control OFM because of the minimal damage caused by insects during that period.

From the second adult population peak to harvest, fruit damage by G. molesta in the control experimental unit was $2.1 \%$ and $7.5 \%$ for the evaluations in early and late January, respectively (Figure 2). Observed damage coincides with findings by Kovanci et al. (2005a) where only late-inseason generations of $G$. molesta caused damage and has since been considered as a late-season pest of apples. If growers can only tolerate a maximum of $1 \%$ to $2 \%$ fruit damage by $G$. molesta at harvest, pest-control efforts should be intensified in December when OFM begins to cause more extensive damage to the apple crop (Figure 2).

Similarly, there was also a significant increase in damage between December and January due to $B$. salubricola and the various Geometridae and Noctuidae species (Figure 2). These results concurred with a previous study conducted by Botton et al. (2000) for B . salubricola. Damage caused by Noctuidae and Geometridae was observed soon after flowering, which suggests that treatments should occur during this period (Kovaleski and Ribeiro, 2003).

The MDI for SG and SGAK treatments was $77.6 \%$ and $84.7 \%$, respectively (Table 1 ). Significantly fewer male G. molesta were trapped in the SG and SGAK treatments than in the experimental units that did not receive SPLAT treatments (Table 1 and Figure 1). This suggests that both SPLAT formulations effectively reduced mate-finding of G. molesta in the pheromone-treated areas. However, SG and SGAK treatments in these 1 ha plots did not significantly reduce fruit damage compared with the areas that did not receive pheromone treatments (Figure 2). The mean percentage of fruit damaged by G. molesta in areas where SG and SGAK were applied was $2.1 \%$ and $1.9 \%$ (January) and 6.3\% and 5.1\% (harvest), respectively, and not different with the untreated control. In contrast, only $0.4 \%$ of the fruit was damaged by G. molesta at harvest in areas under chemical control treatment (IAP) (Figure 2). These results indicate that although pheromone treatments suppressed G. molesta mating in the treated area, they were not effective in reducing gravid female migration and oviposition on the protected fruit of these very small areas. It is important to note that orchards under very high pest pressure surrounded all the experimental plots.

There are many factors known to influence moth capture and the efficiency of mating disruption by attracting and killing OFM in orchards. Such factors include: efficiency of lures and traps (effects of trap design) in attracting moths, condition of lures (in terms of longevity and consistent pheromone release), sticky liners, trap density per unit area, moth population density, climatic factors (i.e., wind direction, speed, and temperature on pheromone release), or microclimatic factors (temperature and relative humidity) (Cardé and Minks, 1995; Molinari, 2002; Lame et al., 2010; Joshi et al., 2011; Pastori et al.,2012). Little is known about mating disruption by attracting and killing in Brazilian apple orchards. In general, semiochemical techniques have been recommended to control G. molesta when infestation is low (Cardé and Minks, 1995; Molinari, 2002). High population densities promote chance encounters between males and females and subsequent mating (Michereff Filho et al., 2000; Molinari, 2002).

Overall, we found that applying SG and SGAK in

Table 1. Mean number of Grapholita molesta males captured in traps and mating disruption index (MDI) in apple orchards receiving two applications (1 August and 1 December 2004) of SPLAT Grafo (SG) or SPLAT Grafo Attract and Kill (SGAK), Integrated Apple Production (IAP), or untreated control.

\begin{tabular}{|c|c|c|c|}
\hline Treatment & Management & Captured males ${ }^{1}($ mean \pm SE) & $\operatorname{MDI}(\%)^{2}$ \\
\hline SG & SPLAT Grafo (1 August and 1 December 2004) & $166.6 \pm 16.0 \mathrm{a}$ & 77.6 \\
\hline SCG & SPLAT Grafo Attract and Kill (1 August and 1 December 2004) & $113.8 \pm 35.6 \mathrm{a}$ & 84.7 \\
\hline IAP & Integrated Apple Production & $746.1 \pm 18.4 b$ & - \\
\hline Control & No treatment & $584.4 \pm 88.1 b$ & - \\
\hline
\end{tabular}

${ }^{1}$ Means followed by the same lower-case letter do not differ significantly according to Tukey's test at 0.05 probability of error; SE: standard error. ${ }^{2} \mathrm{MDI}:($ Treatment $-\mathrm{IAP}) / \mathrm{IAP} \times 100$. 
August and December significantly suppressed trap catches, which suggests that pheromone treatments disrupted mating of $G$. molesta. Fruit damage during harvest was similar for the pheromone-treated experimental units and the untreated control. This suggests a reduced effectiveness of semiochemicals when applied to small areas under high pest pressure. Migration of mated females from areas adjacent to those treated with pheromone has been cited as a major impediment to the success of mating disruption as a opest control method (Cardé and Minks, 1995; Molinari, 2002). The apple orchards surrounding the experimental area were under conventional pesticide management and sustained very high OFM population densities and with freely mating males and females. In the pheromonetreated areas, there were no barriers to stop the migration of mated females from the neighboring areas. Even in pheromone-treated areas with a high mating disruption index, migration of mated females from adjacent areas can result in significant losses, especially around the edges of the field. Furthermore, because OFM females easily travel distances $<200 \mathrm{~m}$ (Il'ichev et al., 2002), they can penetrate deep into the pheromone-protected area. This is also influenced by pest density in the surrounding areas and the edge where female oviposition causes significant damage. If the pheromone-protected area is small, as was the case in this experiment, the edge effect can span over the entire field and completely obfuscate the protective effect of mating disruption in the treated area. In such instances, it is important to make an additional assessment of fruit damage before harvest to either confirm the effectiveness of the semiochemical treatments or to indicate the need of additional control with conventional insecticides.

The efficiency of mating disruption has been related to the size of the treated area (Molinari, 2002) and can also be related to the ability of $G$. molesta males to disperse within and between crops over distances of up to $554 \mathrm{~m}$ (Ellis and Hull, 2012). In growing populations, dispersing males could be more likely to encounter and mate with females, thus reducing the efficiency of semiochemical treatments. Mating disruption is usually effective when applied to large areas ( $>5$ ha) (Molinari et al., 2000; Il'ichev et al., 2004; Kovanci et al., 2004; Pastori et al., 2012). The larger the treated area, the smaller the negative influence of field borders, which are subject to increased pest damage from migrating moths (Molinari, 2002). In the present study, we decided to use smaller areas to reduce the risk of production loss in treatments where pheromone or insecticides were not applied.

Crop damage was also caused by other moth pests, including B. salubricola and species of Geometridae and Noctuidae. This indicates that for growers to adopt semiochemical technologies to control G. molesta, they will have to continue using conventional insecticides to control other Lepidoptera pests. Adopting pheromone products will greatly assist growers in achieving PIM goals. Growers will be able to gradually reduce the target pest population densities over the seasons, decrease insecticide use, and begin establishing larger populations of natural enemies in their fields (Meissner et al., 2001; Trimble et al., 2001; Botton et al., 2005; Kovanci et al., 2005b).

In Brazil, sex pheromone-baited traps are used by growers to monitor OFM populations in orchards treated with OFM sex pheromone. The effectiveness of mating disruption is commonly correlated to trap shutdown, which is defined as the failure of pheromone-baited traps to catch males of the target moth. The effect of mating disruption is more efficient when fewer males are caught by the pheromone-baited monitoring traps.

However, these sex pheromone-baited traps are ineffective in tracking pest populations under these conditions since they do not provide information about the presence of females in orchards, as well as whether the females have been fertilized (Cichon et al., 2012). In future studies, virgin females (Stelinski et al., 2007) and food-bait traps (Cichon et al., 2012) should be used to obtain more reliable information about the efficiency of mating disruption using sex pheromone formulations to control G. molesta.

\section{CONCLUSIONS}

Applying SPLAT Grafo and SPLAT Grafo Attract and Kill in apple orchards significantly reduced the capture of male Grapholita molesta compared with non-pheromone treated areas. The SPLAT formulations, however, were not effective in preventing fruit damage in the small study areas (1 ha) under high G. molesta population pressure. These results suggest that there was a strong edge effect due to the migration of fertilized females from the nonpheromone treated areas. This indicates that larger experimental plots are needed to effectively manage high G.molesta densities using a pheromone-mating disruption technique. There is also a need for thorough knowledge of the history of pest infestation in the area being considered as a candidate for mating disruption control.

\section{ACKNOWLEDGEMENTS}

To Conselho Nacional de Desenvolvimento Científico e Tecnológico (CNPq), Coordenação de Aperfeiçoamento de Pessoal de Nível Superior (CAPES), ISCA Tecnologias Ltda., and ISCA Technologies, Inc. for their support.

\section{LITERATURE CITED}

Atterholt, C.A., M.J. Delwiche, R.E. Rice, and J.M. Krochta, 1999. Controlled release of insect sex pheromones from paraffin wax and emulsions. Journal of Controlled Release 57:233-247. 
Bisognin, M., O.Z. Zanardi, D.E. Nava, C.J. Arioli, M. Botton, and M.S. Garcia. 2012. Burrknots as food source for larval development of Grapholita. Annals of the Entomological Society of America 41:849-854.

Bohnenblust, E., L.A. Hull, and G. Krawczyk. 2011. A comparison of various mating disruption technologies for control of two internally feeding Lepidoptera in apples. Entomologia Experimentalis et Applicata 138:202-211.

Botton, M., F. Kulcheski, V.D. Colletta, C.J. Arioli, e P.L. Pastori. 2005. Avaliação do uso do feromônio de confundimento no controle da Grapholita molesta (Lepidoptera: Tortricidae) em pomares de pessegueiro. Idesia 23:43-50.

Botton, M., O. Nakano, e A. Kovaleski. 2000. Controle químico da lagarta-enroladeira Bonagota cranaodes (Meyrick) na cultura da macieira. Pesquisa Agropecuária Brasileira 35:2139-2144.

Cardé, R.T., and A.K. Minks. 1995. Control of moth pests by mating disruption: Successes and constraints. Annual Review of Entomology 40:559-585.

Cichon, L., E. Fuentes-Contreras, S. Garrido, J. Lago, W. BarrosParada, and E. Basoalto. 2012. Monitoring oriental fruit moth (Lepidoptera: Tortricidae) with sticky traps baited with terpinyl acetate and sex pheromone. Journal of Applied Entomology $4: 275-281$

Degen, T., A. Chevallier, and S. Fischer. 2005. Evolution de la lutte phéromonale contre les vers de la grape. Revue Suisse de Viticulture, Arboriculture et Horticulture 37:273-280.

Ellis, N.H., and L.A. Hull. 2012. Factors influencing adult male Grapholita molesta dispersal in commercial Malus and Prunus host crops. Entomologia Experimentalis et Applicata 146:232241.

González, R.H., G. Barría, y T. Curkovic. 1990. Confusión sexual, un nuevo método de control específico de la grafolita del durazno: Cydia molesta. Revista Frutícola 11:43-49.

Il'ichev, A.L., L.J. Gut, D.G. Williams, M.S. Hossain, and P.H. Jerie. 2002. Area-wide approach for improved control of Oriental fruit moth Grapholita molesta (Busck) (Lepidoptera: Tortricidae) by mating disruption. General and Applied Entomology 31:7-15.

Il'ichev, A.L., D.G. Williams, and A.D. Milner. 2004. Mating disruption barriers in pome fruit for improved control of Oriental fruit moth Grapholita molesta Busck (Lep., Tortricidae) in stone fruit under mating disruption. Journal of Applied Entomology 128:126-132.

Kovaleski, A., e L.G. Ribeiro, 2003. Manejo de pragas na Produção Integrada de Maçã. p. 61-68. In Protas, J.F.S., and R.M. Valdebenito Sanhueza (eds.) Produção integrada de frutas: O caso da maçã no Brasil. Ed. Embrapa Uva e Vinho, Bento Gonçalves, Rio Grande do Sul, Brasil.

Kovanci, O.B., C. Schal, J.F. Walgenbach, and G.G. Kennedy. 2005a. Comparison of mating disruption with pesticides for management of oriental fruit moth (Lepidoptera: Tortricidae) in North Carolina apple orchards. Journal of Economic Entomology 98:1248-1258.

Kovanci, O.B., J.F. Walgenbach, and G.G. Kennedy. 2004. Evaluation of extended-season mating disruption of the Oriental fruit moth Grapholita (Busck) (Lep., Tortricidae) in apples. Journal of Applied Entomology 128:664-669.

Kovanci, O.B., J.F. Walgenbach, G.G. Kennedy, and C. Schal. 2005b. Effects of application rate and interval on the efficacy of sprayable pheromone for mating disruption of the oriental fruit moth Grapholita molesta. Phytoparasitica 33:334-342.

Joshi, N.K., L.A. Hull, E.G. Rajotte, G. Krawczyk, and E. Bohnenblust. 2011. Evaluating sex-pheromone- and kairomonebased lures for attracting codling moth adults in mating disruption versus conventionally managed apple orchards in Pennsylvania. Pest Management Science 67:1332-1337.

Lame, F.M., D. Epstein, L.J. Gut, H. Goldfarb, and J.R. Miller. 2010. Effect of varying dispenser point source density on mating disruption of Grapholita molesta (Lepidoptera: Tortricidae). Journal of Economic Entomology 103:1299-1305.
Larraín, S.P., M. Guillon, J. Kalazich, F. Graña, and C. Vásquez. 2009. Effect of pheromone trap density on mass trapping of male potato tuber moth Phthorimaea operculella (Zeller) (Lepidoptera: Gelechiidae), and level of damage on potato tubers. Chilean Journal of Agricultural Research 69:281-285.

Mafra-Neto, A. 2010. Versatile application of SPLAT for mating disruption and attract and kill programs in agricultural and urban environments. p. 36-36. $84^{\text {th }}$ Annual Meeting Orchard Pest and Disease Management Conference, Portland, Oregon. 13-15 January. Washington State University, Wenatchee, Washington, USA.

Manzoni, G., A.D. Grützmacher, F.P. Giolo, C.A.B. Lima, S.D. Nörnberg, e W.R. Harter. 2006. Seletividade de agrotóxicos recomendados na produção integrada da maçã a Trichogramma pretiosum Riley, 1879 (Hym.: Trichogrammatidae) em condições de laboratório. Revista Brasileira de Fruticultura 8:254-257.

Meissner, H.E., J.F. Walgenbach, and G.G. Kennedy. 2001. Effects of mating disruption and conventional pesticide treatments on populations of the tufted apple bud moth, Platynota idaeusalis, in North Carolina apple orchards. Crop Protection 20:373-378.

Michereff Filho, M., E.F. Vilela, G.N. Jham, A. Attygalle, A. Svatos, and J. Meinwald. 2000. Initial studies of mating disruption of the tomato moth, Tuta absoluta (Lepidoptera: Gelechiidae) using synthetic sex pheromone. Journal of the Brazilian Chemical Society 11:621-628

Molinari, F. 2002. Criteri per l'applicazione del metodo della confusione nella defesa del pesco. Notiziario sulla Protezione delle Piante 14:165-169.

Molinari, F., P. Cravedi, F. Rama, F. Reggiori, M. Dal Pane, e T. Galassi. 2000. L'uso dei feromoni secondo il metodo del "disorientamento" nella difesa del pesco da Cydia molesta e Anarsia lineatella. Atti delle Giornate Fitopatologiche 1:341-348.

Monteiro, L.B., A. Souza, e L. Belli. 2008. Confusão sexual para o controle de Grapholita molesta (Lepidoptera: Tortricidae), em pomares de macieira, em Fraiburgo (SC), Brasil. Bragantia 67:191-196.

Moura, A.P., G.A. Carvalho, and M. Botton. 2012. Residual effect of pesticides used in Integrated Apple Production on Chrysoperla externa (Hagen) (Neuroptera: Chrysopidae) larvae. Chilean Journal of Agricultural Research 72:217-223.

Neto e Silva, O.A.B., M. Botton, M.S. Garcia, A.Z. Bisognin, e D.E. Nava. 2010. Desenvolvimento e reprodução da mariposa-oriental em macieira e pessegueiro. Pesquisa Agropecuária Brasileira 45:1082-1088

Pastori, P.L., C.J. Arioli, M. Botton, L.B. Monteiro, e A. Mafra Neto. 2008. Avaliação da técnica de disrupção sexual utilizando emissores SPLAT visando ao controle de Bonagota salubricola (Meyrick) e Grapholita molesta (Busck) (Lepidoptera: Tortricidae) na pré-colheita de maçãs da cultivar Fuji. BioAssay 3:1-8

Pastori, P.L., C.J. Arioli, M. Botton, L.B. Monteiro, L. Stoltman, and A. Mafra Neto. 2012. Integrated control of two tortricid pests in apple orchards with sex pheromones and insecticides. Revista Colombiana de Entomología 38:224-230.

Pinheiro, J.N., e B.M. Freitas. 2010. Efeitos letais dos pesticidas agrícolas sobre polinizadores e perspectivas de manejo para os agroecosistemas brasileiros. Oecologia Australis 14:266-281.

Protas, J.F.S. 2003. Marcos referenciais da produção integrada de maçã: Da concepção à implantação. p. 13-20. In Protas, J.F.S., and R.M. Valdebenito Sanhueza (eds.) Produção integrada de frutas: O caso da maçã no Brasil. Editorial Embrapa Uva e Vinho, Bento Gonçalves, Rio Grande do Sul, Brasil.

Rothschild, G.H.L. 1975. Control of Oriental fruit moth Cydia molesta (Busck) (Lepidoptera: Tortricidae) with synthetic female pheromone. Bulletin of Entomological Research 65:473-490.

Salles, L.A.B., e L.H. Marini. 1989. Avaliação de uma formulação de confundimento no controle de Grapholita molesta (Busck, 1916) (Lepidoptera: Tortricidae). Anais da Sociedade Entomológica do Brasil 18:329-336. 
Stelinski, L.L., L.J. Gut, R.E. Mallinger, D. Epstein, T.P. Reed, and J.R. Miller. 2005. Small plot trials documenting effective mating disruption of oriental fruit moth by using high densities of waxdrop pheromone dispensers. Journal of Economic Entomology 98:1267-1274.

Stelinski, L.L., J.R. Miller, R. Ledebuhr, P. Siegert, and L.J. Gut. 2007. Season-long mating disruption of Grapholita molesta (Lepidoptera: Tortricidae) by one machine application of pheromone in wax drops (SPLAT-OFM). Journal of Pest Science 80:109-117.

Trimble, R.M., D.J. Pree, E.S. Barszcz, and N.J. Carter. 2004. Comparison of a sprayable pheromone and two hand-applied pheromone dispensers for use in the integrated control of Oriental fruit moth (Lepidoptera: Tortricidae). Journal of Economic Entomology 97:482-489.
Trimble, R.M., D.J. Pree, and N.J. Carter. 2001. Integrated control of Oriental fruit moth (Lepidoptera: Tortricidae) in peach orchards using insecticide and mating disruption. Journal of Economic Entomology 94:476-485.

Vilcker, R.A., G.H. Rothschild, and E.L. Jones. 1985. Control of Oriental fruit moth C. molesta (B.) (Lepidoptera: Tortricidae), at a district level by mating disruption with synthetic female pheromone. Bulletin of Entomological Research 75:625-634. 